\title{
ENSEÑANZA Y RETÓRICA
}

\author{
Nicolás Garayalde \\ Universidad Nacional de Córdoba \\ CONICET-IDH \\ Córdoba, Argentina \\ negarayalde@gmail.com
}

RESUMEN / ABSTRACT

Este artículo se presenta como una continuación, cuarenta años después, del análisis que Gérard Genette desarrolló en "Rhétorique et enseignement" (1966), donde investigó el pasaje de la retórica a la historia literaria que se produjo a principios del siglo XX en el campo de la enseñanza de la literatura. Para desarrollar esta tarea, analizaremos primero la correspondencia entre las transformaciones que se han operado en el campo de los "estudios literarios" y las que podemos observar en el campo de la enseñanza de la literatura. Este trabajo nos permitirá advertir, a partir de la década del 70 y del auge de la teoría literaria, un retorno de la retórica. Pero una nueva retórica: no aquella tradicional de la persuasión sino el despliegue de una retórica ligada a la deconstrucción y a la "crítica intervencionista".

PALABRAS CLAVE: enseñanza, literatura, retórica, historia literaria, teoría literaria.

\section{TEACHING AND RHETORIC}

This article is presented as a continuation, forty years later, of the analysis that Gerard Genette developed in "Rhétorique et enseignement" (1966), where he investigated the passage from rhetoric to literary history that occurred at the beginning of the 20th century in the teaching of literature. To develop this task, we will first analyze the correspondence between the transformations that have taken place in the field of "literary studies" and those that we can observe in the field of literature teaching. This work will allow us to notice, from the 70's and the rise of literary theory, a return of rhetoric. But a new rhetoric: not the traditional one of persuasion but the deployment of a rhetoric linked to deconstruction and "interventionist criticism".

KEYWORDS: teaching, literature, rhetoric, literary history, literary theory. 


\section{INTRODUCCIÓN}

La enseñanza de la literatura ya no será lo que era, lo que ha sido durante, digamos, los últimos cincuenta años. Vivimos hoy un momento de transformación.

Tzvetan Todorov

Las palabras de Todorov son de julio de 1969. Acababa de terminar un extenso coloquio en Cerisy cuyo tema convocante había sido la enseñanza de la literatura y cuyas actas ocuparían seis centenares de páginas. Hacía poco más de un año de mayo de 1968 y en las intervenciones puede percibirse un aire de urgencia, de cambio, de transformación necesaria, a veces incluso de una inercia conservadora de lo que Serge Doubrovsky (1971) llamó "el ensueño dogmático". Ciertamente, parecían tiempos de cambios para el modo de concebir los sistemas de enseñanza; tiempos que requerían una transformación radical.

Sin embargo, no era la primera vez que la enseñanza experimentaba un estado semejante, a pesar del apasionado espíritu transformador de la época. Algo sobre lo que había llamado la atención uno de los participantes del coloquio de Cerisy, aunque tiempo antes, en enero de 1966, en un artículo titulado "Rhétorique et enseignement" -publicado apenas tres meses antes del coloquio, el uno de mayo de 1969, en Figures II:

A decir verdad, nuestra cultura se interesa de una manera mediocre en la historia de los métodos y de los contenidos de la enseñanza. Basta con considerar la forma naif con que la opinión se apasiona alrededor de cada proyecto de reforma para constatar que se trata siempre, en la conciencia pública, de la reforma de la enseñanza [...]: como si no fuera la naturaleza y la norma de la enseñanza el ser una reforma perpetua (23).

Apenas un par de años antes de la conmoción de mayo del 68 -cuyos estandartes cuestionaban el movimiento estructuralista bajo el lema les structures ne descendent pas dans la rue-, Genette se interesa en una transformación anterior, ocurrida hacia finales del siglo XIX, que supuso el relevamiento de la retórica por la historia literaria. ¿En qué consistió este desplazamiento?

En la enseñanza retórica, caracterizada por un acento sobre la elocutio, es decir, la construcción de los tropos, se trataba de poner a los estudiantes en contacto con el texto según un sentido de la imitación: la lectura apuntaba 
finalmente a un arte de escribir, lo que llevaba a "reforzar el carácter literario (estético) de esta formación". En el paradigma de la historia literaria, en cambio, el discurso sobre la literatura es despejado del literario: "ya no se le pide a los alumnos que escriban fábulas o retratos, sino disertaciones sobre la fábula o el retrato, las cuales no deben estar escritas en la forma de su objeto" (29). La literatura pasa de modelo a objeto. Como consecuencia, la retórica no desaparece, se traslada a la literatura misma que, a través de autores como Mallarmé, Valéry o Blanchot, toma la labor de pensarse a sí misma y se vuelve autorreflexiva. Haciendo coincidir crítica y poesía, es a la vez literatura y discurso sobre la literatura. Sin embargo, Genette advierte que este traslado de la retórica no compensa el equilibrio matemático preexistente. Algo que expresa en un revelador esquema:

Siglo XIX: Literatura (Poética) + Enseñanza (Poética y Crítica) $=2$ Poéticas y 1 Crítica.

Siglo XX: Literatura (Poética y Crítica) + Enseñanza (Crítica) $=1$ Poética y 2 Críticas.

Esta historia no se detiene allí, y el propio Genette parece dar cierta indicación de su continuidad en la intervención que presentó tres años después en Cerisy, aunque centrado aún en los modos de ser de la historia literaria como paradigma de la enseñanza. ¿Qué sucedió a partir de entonces con la retórica en la enseñanza de la literatura? ¿Qué otras transformaciones se dieron lugar y afectaron el modo en que la enseñanza se practica, ya sea en las universidades o en los niveles medios? ¿Qué modificaciones sufrió la ecuación con la que Genette cierra su artículo? ¿Qué impactos tuvieron, tienen o deberían tener para la práctica de la enseñanza de la literatura?

El presente artículo contiene la ambiciosa tarea de dar continuación al ensayo de Genette, tras cuarenta años de su publicación. Para pensar estas preguntas y las transformaciones en la enseñanza de la literatura, propondremos algunas pistas que intentaremos fundamentar.

En primer lugar, nos parece importante considerar la articulación que se ha producido históricamente entre el campo de los estudios literarios y el de la enseñanza de la literatura. Creemos que un análisis de tal articulación puede conducirnos a comprender mejor las transformaciones en el campo de la enseñanza y las consecuencias para su práctica. Trabajando sobre las propuestas de autores como Wolfgang Iser, Antoine Compagnon y Jonathan Culler, nuestra primera pista de trabajo consistirá en considerar una correspondencia de la transformación descrita por Genette para el 
campo de la enseñanza con otra que se habría operado en el campo de los estudios literarios. Así, el desplazamiento de la retórica a la historia tendrá su contracara en el desplazamiento que en los estudios literarios se operó de la poética a la estética. Esta primera pista demandará una continuación que nos permitirá arriesgar otras transformaciones operadas en un campo y otro, más allá de aquella que ha trabajado Genette. Este esquema no será más que eso: un esquema. De tal modo que no carecerá de rigidez y reduccionismo. Las correspondencias nunca son perfectamente tales y tendremos oportunidad de señalar sus matices. Sin embargo, nos ofrece la posibilidad de cartografiar las transformaciones producidas, comprenderlas analíticamente y pensar la práctica de la enseñanza que desde allí se despeja. La rigidez y el reduccionismo no es el único problema con el que nos enfrentaremos aquí. Los términos que emplearemos convocan diferentes acepciones y los autores que pueblan los estudios literarios divergen enormemente en la manera de definirlos. Esto significará la necesidad de especificar el modo en que los emplearemos, acudiendo en lo general a la acepción utilizada en un autor determinado.

En segundo lugar, otra pista de trabajo se desprenderá del lugar que la retórica ocupa en las sucesivas transformaciones. Si para Genette la retórica se desplazó de la enseñanza a la literatura, intentaremos ahora seguir su devenir en el pasaje que va de historia a la crítica y de ésta a lo que llamaremos crítica intervencionista. Este proceder nos conducirá a ponderar un regreso de la retórica al campo de los estudios literarios y la posibilidad consecuente de hacerlo en el de la enseñanza.

Finalmente, como consecuencia de esta labor, enfrentaremos una pregunta que diversos autores han ya planteado: ¿Qué articulación es pensable entre la teoría literaria y la enseñanza de la literatura?

\section{DE LA POÉTICA A LA TEORÍA, DE LA RETÓRICA A LA CRÍTICA}

Es interesante que el desplazamiento de la retórica a la historia literaria descrito por Genette coincida, aproximadamente, con la historia de tres grandes momentos que Wolfgang Iser traza en How to Do Theory (2006) a propósito de los "estudios literarios".

Retrotrayéndose hasta Aristóteles, califica el primer momento como poética, a la que entiende como "una receta para hacer obras de arte" (1). La poética se presenta así como la codificación no del estudio de las obras sino de las obras mismas, según una suerte de gramática prescriptiva de la 
literatura. Se trata de un extenso momento que se prolonga a lo largo de los siglos y aparece todavía en el neoclasicismo francés de un Nicolas Boileau, luego de que la Poética de Aristóteles fuese traducida a las lenguas vernáculas y abundantemente comentada. No es sorprendente, por lo tanto, que en el ámbito de la enseñanza impere la retórica como arte de escribir a partir de la imitación.

Sin embargo, Iser plantea que, hacia finales del siglo XVIII, la poética cederá su lugar a la estética a partir del desarrollo del romanticismo. En efecto, la aparición de las teorías románticas del genio permite liberar la literatura de la tutela aristotélica. Al decir de Madame de Staël, "los derechos de la originalidad se establecieron en lugar del yugo de la corrección" (52). Tal es la razón por la cual la novela, como género exento de la reglamentación que pesaba sobre la lírica o la tragedia, adquiere tal importancia durante el romanticismo. Es en este escenario que se produce una absorción de la crítica por parte de la literatura, que Genette observa en el siglo XX en escritores como Mallarmé o Valéry: "considero al poeta -decía ya Baudelaire en 1861como el mejor de todos los críticos" (Genette 229).

El pasaje de la poética a la estética se establece, según Iser, bajo la égida de la posibilidad de conocimiento del arte: "Hacer versus Conocer el arte articuló el cambio operado por la estética" (Iser 1). Ahora bien, el objeto de la estética no era tanto el arte en sí como la verdad a la que el arte nos permitía acceder: Hegel (1989) concibe los estudios literarios como la investigación de cómo el "espíritu" en su camino a la autoconciencia toma cuerpo en una forma artística, quien le presta su "apariencia sensible". Así, de la poética como una gramática se pasa a la estética como una ontología del arte, camino propicio para el conocimiento de la verdad. Al mismo tiempo, el romanticismo adquiere una conciencia de la historia que lo conducirá paulatinamente a una transformación en el rol de los estudios literarios, ya no ligados a una codificación de la literatura sino a su significación histórica. Madame de Staël demandará así a los estudios literarios el análisis de las relaciones de las obras "con las instituciones sociales", a la vez que distinguirá las literaturas según sus coordenadas espacio-temporales. El desplazamiento de la poética a la estética en los estudios literarios descrito por Iser parece por lo tanto corresponderse con aquel que va, según Genette, de la retórica a la historia en la enseñanza de la literatura. En este sentido, éste último afirma en "Rhétorique et enseignement": 
En la conciencia literaria general, el espíritu de la retórica tradicional está muerto, lo sabemos bien, desde comienzos del siglo XIX con el advenimiento del romanticismo y el nacimiento - conjunto- de una concepción histórica de la literatura; pero no es sino un siglo más tarde (en 1902) que la enseñanza secundaria tomará acto de esta revolución desbautizando la clase de Retórica (24).

A lo largo del siglo XIX, esta concepción histórica adquirirá mayor protagonismo en los estudios literarios con el surgimiento del positivismo, desplegando a partir de la segunda mitad del siglo una metodología desarrollada por Gustave Sainte-Beuve e Hippolyte Taine primero y refinada por Gustave Lanson tiempo después.

Sin embargo, una serie de factores afectarán la concepción estética del arte y la utopía cognitiva de la verdad a la que daba acceso. En primer lugar, a comienzos del siglo XX, entra en crisis la concepción holística del arte como un monolito ontológico con una esencia definible que ofrece un acceso a la verdad. En segundo lugar, el desarrollo de una nueva crítica en los Estados Unidos que pregonaba un análisis inmanentista advirtió prontamente la dificultad de sostener la unidad orgánica de la obra -aunque esta fantasía platónica no haya sido nunca abandonada por los protagonistas del New Criticism. Así, el estudio de la estructura textual dio lugar a trabajos que revelaban la ambigüedad inherente de las obras literarias y el conflicto de interpretaciones que ya no podían ser jerarquizadas por una suerte de profesor erudito y feudal ${ }^{1}$. Así, el arte ya no parece cognoscible en el sentido en que lo pensaba la estética y los interrogantes sufren una mutación: ya no se trata de preguntarse ¿qué es el arte? sino ¿en qué condiciones se produce? En el marco de estos factores, a partir de los cuales declina la estética, se produce la emergencia de lo que Iser entiende como teoría. La ontología del arte es reemplazada por una epistemología que reflexiona sobre las dificultades de su conocimiento. En este marco, sufre también un duro cuestionamiento la historia como herramienta de análisis, según un modelo que opondrá un abordaje intrínseco a otro extrínseco de la literatura. El formalismo resultará crucial en este aspecto, en cuanto significó una oposición a las críticas biográficas, sociohistóricas y filosóficas de la literatura. 
En este punto, resulta pertinente preguntarnos: si a la poética correspondió la retórica y a la estética la historia literaria, ¿cuál sería, entonces, el desplazamiento en la enseñanza que se corresponde con el pasaje de la estética a la teoría?

El ensayo de Genette no nombra este nuevo desplazamiento en la enseñanza aunque es protagonista de él. Sin embargo, encontramos en un texto de Jonathan Culler sobre la enseñanza en los Estados Unidos una referencia que puede responder nuestra pregunta:

Las dos partes más importantes del desarrollo de la enseñanza de la literatura en las universidades norteamericanas son el desplazamiento de la historia de la literatura por la crítica literaria en los años que siguieron a la segunda guerra mundial y la nueva importancia, a partir de 1970, de los diversos discursos teóricos: estructuralismo y semiótica, deconstructivismo, feminismo, psicoanálisis, análisis ideológico ("La critique littéraire" 77).

Al desplazamiento de la retórica por la historia literaria habría seguido otro que va de esta última a la crítica literaria. Culler ubica los orígenes de este desplazamiento - para el caso de los Estados Unidos- en la década del 30, con el desarrollo del New Criticism y su posterior éxito en las instituciones educativas. La transformación supone ahora tratar la literatura como objeto artístico y no como documento histórico, indagando la estructura lingüística que le da forma: "el objetivo ya no es transmitir un saber histórico sino discutir las interpretaciones posibles" (Culler, "La critique littéraire" 123). El propio Genette, en la ponencia presentada en Cerisy, parecía también pensar la crítica, para el caso europeo, como nuevo avatar que venía a desplazar a la historia, al afirmar que aquella "no puede ser histórica porque consiste siempre en una relación directa de interpretación (...) entre el crítico y la obra, y esta relación es esencialmente anacrónica" (Genette, "Littérature et histoire" 248). En un sentido equivalente, empleando casi las mismas palabras, Culler decía lo propio al referirse al New Criticism: "El objeto de esta crítica ya no es la construcción de una historia de la literatura sino la interpretación de obras de arte individuales" ("La critique littéraire" 77).

De la retórica (poética) a la historia (estética), y de la historia a la crítica (teoría). Pero estos pasajes no son tan sencillos como parece y su formulación no carece del reduccionismo propio de todo esquema. En realidad, la sustitución de la historia por la crítica no fue sino parcial. Los nuevos críticos ocuparán prontamente las universidades y el modelo de análisis inmanentista se 
dispersará en las instituciones como paradigma hegemónico pero sin terminar de expulsar la historia de las cátedras de literatura. Así, el desplazamiento de la historia a la crítica que estamos describiendo se produce en el marco de cierta convivencia y no de acuerdo a una simple sustitución. Al referirse a los cursos de literatura en las universidades norteamericanas durante la década del 60, Culler advierte una formación heterogénea entre el análisis inmanente y la historia literaria:

Incluso si los profesores de estos cursos no sostienen un discurso propiamente historicista [...], aquellos que se dedican a la crítica y a la interpretación son considerados, como todos los sabios, especialistas de un período. Además, los puestos permanecen definidos por períodos -Edad Media, Renacimiento, Siglo XVIII, Romanticismo, Edad victoriana, Modernidad [...]. Estas estructuras universitarias dan a la enseñanza de la literatura un carácter algo vago: en el caso típico, las categorías históricas que proveen el marco de los estudios literarios no son respetadas, y el objeto se vuelve la interpretación de cada obra en particular, pero las consideraciones teóricas que justificarían tal forma de proceder no están representadas en las estructuras del programa ("La critique littéraire" 80).

Esta convivencia de la crítica y la historia literaria se revela significativamente en la perseverancia de una perspectiva histórica de la literatura frente al proyecto estructuralista que Jean-Yves Tadié formula en la introducción del extenso cuadro de la literatura francesa de 1600 páginas que publicó en 2007:

Hubo a mitad del siglo XX una crisis de la historia como relato. Deseosos con todo derecho de dar cuenta de las grandes estructuras que atraviesan el tiempo, se estuvo a punto de perder el sentido y el sentimiento del pasado. Aquello que fue una hipótesis de investigación fecunda en una cátedra o un laboratorio se volvió una caricatura y una catástrofe, alcanzando los programas de los liceos veinte años más tarde (23).

La expresión de Culler y el malestar de Tadié manifiestan las tensiones todavía presentes en las universidades francesas y norteamericanas entre la crítica y la historia literaria. Pero la afirmación de Tadié expresa algo más: el modelo estructural, absorbido por las instituciones educativas, devino una caricatura, un método aplicable, una receta analítica que hizo del manual su hábitat de reproducción: 
El estructuralismo -señala por su parte Analía Gerbaudo, pensando en el caso argentino- fue la panacea de la pedagogía y de la despolitización: las metodologías estructuralistas no sólo confieren un conjunto de procedimientos fijos que permiten acceder a las interpretaciones legítimas sino que confían en que es posible extraer la verdad del texto, delimitada por los límites del sistema a analizar. En nombre de la ciencia, se abortan las capacidades subversivas del texto. [...] Mientras tanto, los docentes, tranquilos (y las instituciones también) ("Pluralismo teórico" 65).

No solo la historia literaria sobrevivió al abordaje interno desarrollado por la teoría; este mismo abordaje se constituyó en el seno de una paradoja: si se posicionó frente a la historia literaria dominante en las universidades como una crítica pública y anti-universitaria, no tardó sin embargo en ser devorado por las mismas instituciones que cuestionaba, volviéndose digerible, aplicable. Bajo la forma del método, la crítica literaria se convirtió por lo tanto en una rejilla que hacía de la heterogeneidad literaria un fenómeno homogéneo y generalizable. Tal es la razón por la cual desde su mismo seno hubo de producirse un desplazamiento que podríamos llamar intrateórico y que se corresponde con la segunda parte a la que alude Culler al referirse al pasaje de la historia literaria a la crítica. A partir de la década de 1970, una transformación se operó al interior de la teoría facilitada por los mismos presupuestos que la gestaron, en una suerte de deconstrucción de sus principios metafísicos.

¿En qué consistió este desplazamiento y qué consecuencias tiene para la enseñanza de la literatura?

\section{TEORÍA DE LA LITERATURA Y TEORÍA LITERARIA}

La necesidad de establecer una distinción en el marco de la teoría literaria puede advertirse en la significativa oscilación con la que Antoine Compagnon, en la introducción de Le démon de la théorie, emplea los sintagmas teoría de la literatura y teoría literaria. Si durante las primeras páginas estos términos son indistintamente utilizados, en un determinado momento Compagnon se ve conducido a establecer una distinción entre ambos:

La teoría de la literatura designa la reflexión sobre las condiciones de la literatura, de la crítica literaria y de la historia literaria. [...] La teoría literaria es más oposicional y se presenta más bien como 
una crítica a la ideología, incluida la de la teoría de la literatura. (...) Como lo recordaba de Man, la teoría literaria surge [vient à l'existence] cuando el abordaje de los textos literarios ya no se funda en consideraciones no-lingüísticas, por ejemplo históricas o estéticas, sino cuando el objeto de la discusión ya no es el sentido o el valor sino las modalidades de producción del sentido o del valor (23-24, el subrayado es nuestro).

Es necesario advertir que el panorama histórico de los estudios literarios que propone en este libro Compagnon no encaja perfectamente con el de Iser. Pocas páginas antes de este fragmento, el teórico francés describe una transición que va de la poética a lo que llama, en ese momento, "teoría de la literatura moderna", y cuyos orígenes encuentra, precisamente, en el romanticismo. Se trata de una teoría que "se relaciona con la filosofía de la literatura, como rama de la estética, la cual reflexiona sobre la naturaleza y la función del arte, sobre la definición de belleza y del valor" (18). Así, Compagnon subsume la estética en la teoría de la literatura. Es por ello que en esta última existe una coincidencia de la historia literaria y la crítica como efectos sobre una práctica de la enseñanza y análisis de la literatura.

Por su parte, la teoría literaria emerge cuando la literatura ya no se aborda por consideraciones no lingüísticas. Es decir, cuando se abandona la estética y la historia literaria. Esta idea de Compagnon es interesante: la focalización de la teoría literaria sobre el lenguaje -cuyos orígenes sitúa en el formalismo- ofrece la posibilidad de dirigir una crítica a la ideología, a la que entiende como "las ideas recibidas", es decir, como el "sentido común", pero a la que deberíamos entender también, por la referencia a Paul de Man, como la creencia en la correspondencia del signo y el referente. La referencia a de Man no es por lo tanto casual, pues permite establecer un camino retroactivo en el que la teoría literaria se ha configurado en tensión con la teoría de la literatura. Así, si bien podríamos ubicar la época dorada de la teoría literaria "a partir de 1970" -para emplear el mojón de Culler-, es posible rastrear su prehistoria mucho antes, comenzando, como ya hemos visto, por el formalismo y siguiendo por el New Criticism. En el primero -cuyas metáforas organicistas revelan una metafísica propia de la teoría de la literatura-, se establece un primer cuestionamiento a la historia literaria en pos de un análisis lingüístico que se concentra sobre la lengua poética; en el segundo -cuya afición por la unidad orgánica revela también su tradición metafísica-, la noción de ambigüedad exhibe ya el señalamiento a la falta de fundamento natural de los textos. 
Tanto el New Criticism como el estructuralismo tenían en sus fundamentos constitutivos los elementos que llevarían a una deconstrucción del sistema propuesto. Esta es la razón por la cual Paul de Man afirmaba que uno de los libros fundantes del New Criticism -Seven Types of Ambiguity, de Williamp Empson- era a la vez un texto precursor de la deconstrucción norteamericana; esta es la razón por la cual, también, los nombres del "periplo estructural" (Milner 2003) en Francia han sido los mismos que propusieron "a partir de 1970" un giro que las clasificaciones académicas estilan llamar "posestructuralismo". En uno y otro caso, se trata de un síntoma de las contradicciones que habitaban la crítica que venía a reemplazar a la historia literaria (a partir del pasaje de la estética a la teoría). Podríamos decir que la teoría de la literatura supone aquella parte de la teoría que se constituye a partir de la herencia estética recibida, mientras que la teoría literaria se configura a partir de un cuestionamiento a los preceptos metafísicos e ideológicos de la teoría de la literatura.

Lo interesante de esta transformación fue por lo tanto la problematización de algunos elementos heredados de la tradición metafísica que sustentaban la universalidad del arte y la unidad orgánica de la obra. El fenómeno es complejo, y otra tesis de Iser, desarrollada esta vez en El acto de leer, puede ayudarnos a comprenderlo: cuando el arte moderno se vuelve parcial y abandona las pretensiones de universalidad, es la "interpretación tradicional" (Iser no lo explicita, pero se refiere aquí a lo que en How to Do Theory llamará la estética) la que toma con el romanticismo las pretensiones universalistas: "Pues cuanto más comienza el arte a asumir un carácter parcial, tanto más universal se hace la pretensión explicativa de la interpretación que se le dedica" (Iser, El acto de leer 31). La fantasía de esta interpretación se articula a preceptos metafísicos que se trasladarán a distintos abordajes de la teoría de la literatura, como el New Criticism, el estructuralismo y la hermenéutica gadameriana (al menos la de Verdad y Método): el orden, la armonía, la consonancia, la unidad orgánica. Así, es esta herencia lo que a partir de 1970 se pondrá en cuestión con el pleno desarrollo de la teoría literaria. Fenómeno que se produce en el marco de la irrupción interdisciplinar de lo que Culler llama "teoría" a secas y que designa "las obras que logran comprometer e incluso modificar el pensamiento más allá de los dominios a los que se supone pertenecen porque sus análisis del lenguaje, del pensamiento, de la historia o de la cultura ofrecen nuevas y prometedoras perspectivas sobre la significación" (Culler, Literary Theory 81). Esta noción de teoría no se adecua ya entonces a la idea de un conjunto de métodos para el estudio literario. Todo lo contrario: tal como lo 
señala Compagnon en Le démon de la théorie, "la fatalidad de la teoría es la de ser transformada en método por la institución académica” (15). ¿En qué consiste, pues, este nuevo modo de ser de la teoría?

Si seguimos el pensamiento de Culler, podría ser entendida como una práctica analítica, especulativa y reflexiva interdisciplinaria que tiene por objetivo una crítica al sentido común, es decir a "los conceptos tomados como naturales" (Literary Theory 15). También Compagnon enfatiza este aspecto para proponer su definición de teoría: "Hay teoría cuando las premisas del discurso ordinario sobre la literatura ya no son aceptados como algo dado, cuando son cuestionadas, expuestas como construcciones históricas, como convenciones" (15). Y más adelante: "La teoría se opone al sentido común" (19). Por su parte, Hillis Miller, deconstruccionista de la Universidad de Yale, se inscribe en esta misma concepción al señalar que "la función de la teoría es la de liberarnos de la ideología, incluso de la ideología de la teoría misma". Y agrega inmediatamente: "La teoría crítica, desde este punto de vista, se gana su etiqueta de crítica" (202). Recuperando esta aclaración de Miller -y para evitar malentendidos terminológicos-, convendría hablar entonces de un desplazamiento intrateórico que va de la teoría de la literatura a la teoría literaria crítica ${ }^{2}$.

El análisis lingüístico -como herramienta característica de la teoría literaria crítica- decanta en un afinamiento retoricista que encuentra en Paul de Man su mayor exponente: sus investigaciones ponen en escena las tensiones entre la gramática y la retórica, exhibiendo la fractura de la unidad orgánica de la obra, la ilegibilidad como experiencia ineludible de la lectura, la imposibilidad de tomar una decisión sobre el sentido de los textos sin la represión de otro sentido que lo contradice pero que es igualmente válido.

En este contexto, la epistemología de la teoría que había reemplazado a la ontología de la estética parece radicalizarse aún más y pone definitivamente en cuestión la posibilidad del conocimiento del objeto literario. El objetivo ya no es el encuentro de la verdad detrás de la obra (como para la estética) o en la obra (como para la teoría de la literatura), sino la puesta en escena de la falta de fundamento de la verdad, entendida como un proceso incesante

2 También un autor como George Landow emplea la etiqueta de "crítica" para referirse a la teoría literaria que surgió a partir de los años 70 de la mano de autores como Roland Barthes, Jacques Derrida o Gilles Deleuze. $C f$. Landow (2009). 
y paradójico de elaboración de sentido en el que está involucrado el sujeto -como proceso de subjetivación- de la interpretación (teoría literaria crítica).

El análisis hasta aquí desarrollado nos permite despejar por lo tanto una serie de transformaciones tanto en los estudios literarios como en la enseñanza de la literatura que conviene exponer con claridad: poética (retórica) - estética (historia literaria) - teoría de la literatura (crítica e historia literaria) - teoría literaria crítica. Surge entonces la pregunta: ¿qué correspondería en la enseñanza de la literatura para lo que aquí entendemos como teoría literaria crítica? ¿Qué puede ofrecer la teoría literaria para la enseñanza de la literatura?

\section{EL RETORNO DE LA RETÓRICA}

\section{Ha llegado quizás el momento de integrar más retórica en nuestra cultura del comentario. \\ M. Escola y S. Rabau}

La articulación entre la enseñanza y la teoría literaria se establece en una zona de borde que diversos críticos han visitado, procurando pensar los aportes que la segunda puede ofrecer a la primera. En Argentina, esta cuestión ha interesado particularmente a diversos teóricos de la literatura como Jorge Panesi (2014), Analía Gerbaudo (2005; 2009) o Gabriel Bombini (1996; 2009). Señala este último: "La construcción de una didáctica de la literatura y el reconocimiento de la productividad de la teoría literaria en su proceso ha sido, en general, una tarea postergada" ("Didáctica de la literatura" 4).

Para los fines de este artículo, nos interesa señalar una de las consecuencias notables de esta articulación entre la teoría literaria y la enseñanza de la literatura: el regreso de la retórica. ¿Cómo se produce este regreso y cuál debería ser su impacto para la enseñanza de la literatura?

\subsection{RETÓRICA Y LECTURA}

Podríamos decir que este regreso se produce en dos niveles, evidentemente vinculados, lógicamente consecutivos, que ha dado lugar a una nueva modalidad crítica y pedagógica, de acuerdo a lo que Michel Charles (1985) ha llamado "cultura retórica". Dos niveles que se corresponden con un cuestionamiento a la concepción del texto como una estructura estable, por un lado, y con un entrelazamiento entre la crítica y la literatura, por el otro. 
Por un lado, entonces, la retórica se presenta como el arma privilegiada del objetivo principal de la teoría literaria: la desnaturalización, la desmitificación, la crítica a la ideología.

Se trata de un proceso ya iniciado por la semiología, allí donde Roland Barthes había señalado, pensando precisamente la enseñanza de la literatura, el pasaje operado en el campo literario de la mathesis -es decir, la ciencia del conocimiento de la literatura como "un campo completo del saber"- a la semiosis: "es decir, una puesta en escena de lo simbólico, no del contenido, sino de los rodeos, de las vueltas, en resumen de los goces de los simbólico" (882). La agudeza de Barthes le permitía ya ver que este proyecto, que Paul de Man llevaría aún más lejos reemplazando la semiología por la retórica, supondría una resistencia: "Es probable que la sociedad resista a la semiosis, a un mundo que sería aceptado como un mundo de signos, es decir, sin nada detrás" (883, el subrayado es nuestro). Una década después, de Man constatará esta previsión de Barthes: "La resistencia a la teoría es una resistencia a la dimensión retórica o tropológica del lenguaje" (The Resistance 17).

En Allegories of Reading (1979), de Man destaca el trabajo de la semiología francesa como movimiento desmitificador que hace "estallar el mito de la correspondencia semántica entre signo y referente", en el marco de un giro lingüístico que no se pregunta por lo que significan las cosas sino por el modo de su significancia. Sin embargo, de Man reclama un giro retórico que supere la confusión de la semiología entre la gramática y la retórica, de tal modo que "el estudio de los tropos y de las figuras (que es como utilizo aquí el término retórico y no en el sentido derivado de comentario, de elocuencia o persuasión) se convierte en una mera extensión de los modelos gramaticales" (Allegories 6). Ni la elocuencia de la antigua enseñanza de la retórica (cuyo acento estaba en la elocutio como arte de la imitación) ni el comentario de la disertación histórica (cuyo énfasis radicaba en la dispositio, el plan de la composición); la retórica que regresa con Paul de Man es el estudio de los tropos a través de una lectura atenta (close reading) que sea capaz de dar cuenta del modo en que el texto se deconstruye a sí mismo por las aporías que surgen de la naturaleza figurada del lenguaje. Es sintomático en este sentido que inmediatamente después de esta afirmación, de Man evoque un artículo donde Genette analiza la obra de Proust sin advertir las tensiones lógicas entre la gramática y la retórica, sucumbiendo a la creencia de su posible conciliación.

En este sentido, la retórica demaniana es absolutamente opuesta a aquella que sirve de vía para la comprensión hermenéutica de los textos, tal como 
puede advertirse en uno de los padres del New Criticism, I. A. Richards, quien entendía la retórica como "el estudio de los malentendidos y sus remedios" (3). En el marco del sueño comunicativo transparente que Richards anhelaba para los estudios literarios, su retórica se ubica en las antípodas de Paul de Man: herramienta para llegar a la comprensión a pesar de la pluralidad semántica, en uno; instrumento de la narración de la ilegibilidad, en el otro. El giro retórico demaniano supone así un cuestionamiento a la concepción del texto como una estructura estable, a la posibilidad de la lectura como una decisión trascendentalmente fundamentada, a la perspectiva orgánica que anhela la unidad de la obra como resultado interpretativo y a la posibilidad de universalización que pretende la gramática como método explicativo de los textos. Esta posición lleva a de Man a pedir la incorporación de la retórica en la enseñanza de literatura frente a la hermenéutica y a la historia literaria:

Implicaría un cambio a partir del cual la literatura, en lugar de ser enseñada sólo como una materia histórica y humanística, debería ser enseñada como retórica y poética antes que como hermenéutica e historia. Sin embargo, es probable que las resistencias institucionales a este cambio sean insuperables. Ante todo, cambia los departamentos de inglés para que dejen de ser grandes organizaciones al servicio de todo menos de aquello que es su propia materia [...]. Así como también requiere un cambio en la lógica de la enseñanza de la literatura, lejos de las normas de excelencia cultural que, en última instancia, se basan siempre en alguna forma de fe religiosa, para desplazarse a un principio de incredulidad que no es tanto científica como crítica, en el sentido filosófico del término. Se ve con facilidad por qué es probable que estos cambios no ocurran. Aun así, con las cartas críticas tan sobre la mesa como para querer ignorar su existencia, aquellos que rechazan el crimen de la implacabilidad teórica ya no pueden esperar tener la conciencia tranquila. Tampoco, por supuesto, los teóricos; pero ellos nunca reclamaron tal cosa (De Man, The Resistance 26).

Resulta evidente que desde este punto de vista, la enseñanza entra en tensión con el método, cuyo dogmatismo conduce a una "forma de fe religiosa". La incredulidad que reivindica de Man se sustenta precisamente en el retoricismo que afecta toda creencia en el fundamento trascendental de la interpretación. En este punto, de Man manifiesta una filiación con el formalismo que va más allá de la voluntad de alejarse de la concepción referencial de la literatura y comulga con una cierta idea de literaturidad: la retórica se vuelve necesaria porque en ella reside la clave de acceso de aquello que es "la propia materia" 
de los departamentos de literatura. Esto es, la prevalencia de la dimensión retórica de la literatura en comparación con otros tipos de lenguajes. La literatura es por lo tanto un lenguaje consciente de la distancia que separa el signo del referente y su enseñanza; la materia de los departamentos de literatura radica precisamente en la enseñanza de esta dimensión privilegiada y singular ${ }^{3}$. En otras palabras: aquello que se debe enseñar a partir de la teoría literaria - aquello que es en definitiva enseñable- no es un saber del método que permita abordar la literatura en su sentido (determinado ya por la inmanencia de su estructura, ya por su historicidad) sino la resistencia misma a su lectura. Barthes no estaba lejos de este objetivo de la enseñanza -aunque no haya sido la retórica su vía de concreción- cuando afirmaba en "Littérature/enseignement" que se trata de "estremecer la verdad", "hacer temblar la diferencia, el plural" (886).

Este retorno de la retórica como estudio de los tropos es para Hillis Miller un elemento de capital importancia en el cuestionamiento a un conjunto de presupuestos metafísicos de los estudios literarios, comenzando por la creencia de que la lectura debe consistir en limpiar el texto de los adornos retóricos para descifrar el sentido del lenguaje literal:

El cuestionamiento de los retóricos actuales a la enseñanza que asume que las figuras del discurso son o deberían ser ornamentos agregados a una base literal del discurso está indisolublemente asociado con un conjunto de otros cuestionamientos: un cuestionamiento a la idea de que un yo [self] unificado y preexistente utiliza el lenguaje como una herramienta de expresión para escribir con una intención; un cuestionamiento a la idea de que los escritores tienen un argumento claramente establecido en sus mentes que luego copian en las palabras [...]; un cuestionamiento de la idea de que una buena obra debe o puede ser "orgánicamente unificada"; un cuestionamiento al paradigma del "realismo" que asume que la buena escritura debe ser verificada por su correspondencia con alguna realidad externa (236).

\footnotetext{
Nos parece pertinente señalar aquí otro tipo de resistencia, esta vez la del propio de Man, quien se rehúsa a abandonar -en tiempos en los que el objeto literario se ha vuelto incierto (Robin 1989) - una concepción de la literatura como discurso privilegiado. Así, es posible percibir en el pensamiento demaniano una característica propia de la literatura ligada a su autoconciencia que le permite evadir la confusión ideológica entre el signo y el referente.
} 
Tanto en este ensayo de 1983, como en uno anterior de 1979 titulado "The Function of Rhetorical Study at the Present Time", Miller establece una distinción entre dos ramas de la retórica, alineándose en la posición de Paul de Man: por un lado, la retórica de la persuasión -vinculada al arte de escribir, aquella de la que daba cuenta Genette en su artículo-; por otro, la retórica de los tropos -vinculada al arte de leer como descomposición, como interpretación de las figuras del discurso. Para Miller, una retórica de la lectura es necesaria para la enseñanza de una retórica de la persuasión: "aprender a escribir bien no puede ser separado de aprender a leer bien" (204).

Desde este punto de vista, la enseñanza de la retórica de los tropos se despliega en una doble dimensión.

Por un lado, se trata de un estudio de la manera en que se produce la significación de modo tal que se exhiban las fallas que sustentan los preceptos metafísicos de la interpretación: la posibilidad de la reducción de la figura a su sentido literal; la concepción de la transparencia del lenguaje; la percepción de la obra como unidad orgánica; la correspondencia del signo con el referente, del texto con la realidad. Es por esta razón que la teoría literaria, que Miller llama "teoría crítica", "se vuelve en nuestras instituciones educativas uno de los medios más poderosos e indispensables para desenmascarar los supuestos ideológicos" (203). En este aspecto, la teoría literaria se solapa con la retórica de los tropos: "Quiero decir por teoría literaria -dice Miller-el desplazamiento de los procesos hermenéuticos de identificación del sentido de una obra literaria a la focalización sobre los problemas de cómo se genera el sentido" (202).

Por otro lado, establecido el fundamento epistemológico que asume la lectura como un acto de escritura, la retórica de los tropos facilita el desarrollo de una retórica de la persuasión que se despliega no solo hacia el comentario sino, como podremos ver a continuación en algunos críticos franceses contemporáneos, hacia la literatura misma, introduciendo poética en la crítica. La retórica retorna, entonces, según una articulación entre la enseñanza de la lectura y la enseñanza de la escritura. Es decir, de acuerdo a lo que Michel Charles llama una "cultura de la retórica": "consideramos entonces que una cultura retórica es una cultura donde la lectura se dirige hacia una escritura" (L'arbre et la source 185). 


\subsection{RETÓRICA Y ESCRITURA}

El regreso de la retórica supuso así un cuestionamiento -desarrollado además por los deconstruccionistas, notablemente por Geoffrey Hartman- de las fronteras que separan la literatura de su comentario. ¿Significa esto que la enseñanza debe volver a implicar, como antiguamente, el arte de escribir? Desde este punto de vista, la enseñanza no supondría solo una puesta en escena de la imposibilidad del establecimiento de la verdad del texto a través de un método adecuado; la misma puesta en evidencia de la falta de fundamento de la lectura habilita su posible intervención.

En un coloquio celebrado en Oléron en abril de 2003, Marc Escola y Sophie Rabau abren la reunión reflexionando sobre la retórica como "el eterno retorno de lo reprimido" y recuerdan la distinción que Genette había establecido para los estudios literarios entre la "función crítica" y la "función poética": "Podemos preguntarnos - dicen Escola y Rabau- si, desde este artículo de 1969, Genette no estaba ya en la búsqueda de otro tipo de enlace entre la función poética y la crítica" (13). Pero no es la retórica de la imitación aquella que renovaría una nueva conjunción de la poética y la crítica. Se trata de una retórica que, en la estela de Michel Charles, no se interesaría tanto en el análisis del texto tal como es sino en la ponderación de aquello que podría haber sido. Dos elementos fundamentales entran en juego en esta perspectiva: el estatuto epistemológico del texto; el papel del lector.

En Introduction à l'étude des textes (1995), Michel Charles denuncia dos prejuicios sobre el texto propios de la cultura del comentario. En primer lugar, la creencia de la existencia objetiva del texto: "todo sucede como si el texto existiese por fuera de la mirada que recae sobre él, por fuera de las operaciones que le hago sufrir para que precisamente devenga texto" (Introduction 40); en segundo lugar, la creencia en la unidad del texto, a partir de la cual se considera el texto como un objeto "cerrado": "Clausura, unidad, identidad son tres nociones inseparables" (Introduction 41). Prejuicios que pretenden reprimir con su método aquello que, para Charles, es constitutivo del texto: su inestabilidad; su falta de unidad.

Esta misma percepción de la inestabilidad del texto aparece en la crítica de Pierre Bayard: "La imagen que me hago del texto literario -afirma- es la de un objeto inestable que la presencia del lector, y sobre todo su inconsciente, no cesa de animar" ("Comment j'ai fait" 19). A diferencia de Charles, la inestabilidad del texto se traza fundamentalmente sobre la incidencia del inconsciente del lector durante la experiencia de lectura. De modo tal que 
hay en Bayard una elaboración teórica que recurre al psicoanálisis para construir una teoría de la lectura. Pero las consecuencias sobre la cultura del comentario son las mismas: cuestionamiento de sus presupuestos fundamentales (identidad, unidad, clausura, objetividad) y desarrollo de una crítica que imagina los textos que podrían haber sido. En todo caso, puesto el acento sobre el inconsciente, Bayard llega aún más lejos en su manera de concebir la retórica a la que asume como subjetiva, punto preciso por el cual se vuelve posible abrir otros textos posibles a través de la elaboración de una figura del discurso.

Así, en Le hors sujet (1994) es la dificultad de la identificación de la figura de la digresión lo que permite a Bayard elaborar aquello que llama una "retórica movediza" (116). Proponiéndose eliminar las digresiones de À la recherche du temps perdu de Marcel Proust -obra que considera demasiado extensa-, el crítico francés enfrenta prontamente el problema de saber cuándo, objetivamente, está frente a una digresión que puede eliminar. En la medida en que la digresión supone aquello que está por fuera del tema (Dis-gradior: andar por fuera), su identificación requiere tanto el reconocimiento del tema como de la relación que mantiene con él, lo que supone dos problemas que no pueden resolverse sino mediante un acto subjetivo de lectura. Por un lado, ¿cuál es el tema de un texto para reconocer aquello que queda por fuera de él? Por otro, ¿en qué medida el fragmento sospechado de digresión es o no necesario para el tema? Este último problema conduce a otro, vinculado al acto explicativo de la digresión: en cuanto una digresión es analizada y explicada, dice Bayard, su falta de necesidad se diluye junto a su naturaleza digresiva.

En Qui a tué Roger Ackroyd? (1998), primera entrega de la crítica policial de Bayard, es la figura de la elipsis la que permite el trabajo de intervención sobre el texto. Es la posibilidad de interpretar que el supuesto asesino de la novela de Agatha Christie ha callado algo en un momento determinado -mediante lo cual la interpretación de Bayard elabora una elipsis- que el crítico francés se permite completar ese espacio vacío mediante un acto de lectura que reconfigura el sentido del texto y permite elaborar otro en su lugar: otro en el que el asesino no es aquel al que el investigador -Poirot- apunta.

El trabajo sobre las figuras -cuya emergencia ocurre entre la lectura y la escritura- es la vía de acceso a un tipo de crítica que Bayard llama intervencionista: "Lejos de permanecer inactivo frente a las obras y los autores, como la mayor parte de mis colegas, no dudo en intervenir para hacerles sufrir transformaciones y volverlas más conformes a lo que podrían o deberían ser" ("Comment j'ai fait" 20, el subrayado es nuestro). 
Amén de las diferencias - que aquí omitimos por razones de pertinenciaentre Charles y Bayard, ambos representan el espíritu de una crítica intervencionista que surge como consecuencia de un retornar de la retórica según una concepción de la lectura como acto de escritura. Tal es la razón por la cual todos los participantes del coloquio de Oléron citan a uno y a otro como referentes de aquello que llaman la "teoría de los textos posibles" y cuya práctica conduce a una "pedagogía de los textos posibles":

Una teoría de los textos posible producirá todavía una forma de comentario, en cuanto, al proceder a un análisis de un texto dado, establecerá la gramática de sus posibles para proyectar a partir de allí otros textos como "variantes" lógicamente posibles. De esta forma, el ejercicio escolar del comentario puede unirse a ciertas tendencias de la creación contemporánea, y la enseñanza de las letras reconciliarse así con esa tradición retórica que la ha animado durante tanto tiempo (Escola y Rabau 25).

La posibilidad de una pedagogía de los textos posibles podría llevarnos a la misma inquietud de Paul de Man que citamos más arriba. La crítica intervencionista "implicaría un cambio a partir del cual la literatura, en lugar de ser enseñada solo como una materia histórica y humanística, debería ser enseñada como retórica y poética antes que como hermenéutica e historia. Sin embargo, es probable que las resistencias institucionales a este cambio sean insuperables". Sin duda, una retórica y una poética distantes en sus prácticas de aquella que pensaba de Man, pero no de sus presupuestos epistemológicos.

Una pedagogía así planteada -fundamentada en un cuestionamiento generalizado a los presupuestos metafísicos de la teoría de la literaturasupone problemas que difícilmente no atraigan la resistencia institucional. En particular, el del uso de la literatura -frente a la interpretación, para recuperar una distinción de Umberto Eco (1990): ¿todo es entonces válido? Supone asimismo problemas vinculados al modo en que tal enseñanza podría inscribirse y llevarse a cabo en las instituciones educativas.

Pero más allá de estos problemas -que el presente artículo no pretende abordar-, parece evidente que el desarrollo de la teoría literaria en el campo de los estudios literarios exige un retorno de la retórica en su doble dimensión: como práctica deconstructiva de la lectura; como práctica crítica e intervencionista de la escritura. 


\section{CONCLUSIÓN}

En este artículo nos hemos interesado en el desarrollo histórico de la continuidad de las transformaciones descritas por el artículo de Genette "Rhétorique et enseignement".

Para llevar a cabo esta tarea, hemos creído pertinente pensar las transformaciones que se han operado en el campo de los "estudios literarios" (Iser 2006) para articularlas después a aquellas que pudimos observar en el campo de la enseñanza de la literatura. Siguiendo de cerca las propuestas de autores como Iser, Culler o Compagnon, advertimos una serie de desplazamientos en un campo y otro que implicaron un sistema de correspondencias: poética (retórica) - estética (historia literaria) - teoría de la literatura (historia literaria y crítica) - teoría literaria crítica (retórica de los tropos y crítica intervencionista).

El trabajo analítico sobre estas transformaciones históricas en los estudios literarios y su correspondencia en la enseñanza de la literatura nos ha permitido advertir, a partir de la década del 70 y del auge de la teoría literaria, un retorno de la retórica. Retorno que no supuso un regreso a la tradicional retórica de la persuasión sino el despliegue de una retórica doble: como arte del bien leer y del bien escribir. Este retorno ha supuesto tanto un cuestionamiento de los presupuestos metafísicos que habitan los estudios literarios como acercamiento de la crítica a la literatura. Para el beneplácito de un Genette que dejaba traslucir cierta nostalgia por los tiempos en los que en la enseñanza daba mayor lugar a la poética en la ecuación con la que cierra "Rhétorique et enseignement", el retornar de la retórica transforma la lógica matemática tanto del siglo XIX como del XX. Ya no de la imitación, sino de la invención a partir de los textos posibles que se abren a través de las figuras que habitan cada texto, la crítica es a la vez discurso sobre la literatura y literatura; así como esta última es literatura y discurso sobre la literatura. Algo que esquemáticamente podríamos proyectar de la siguiente manera:

Siglo XIX: Literatura (Poética) + Enseñanza (Poética y Crítica) $=2$ Poéticas y 1 Crítica.

Siglo XX: Literatura (Poética y Crítica) + Enseñanza (Crítica) $=1$ Poética y 2 Críticas.

Siglo XXI: Literatura (Poética y Crítica) + Enseñanza (Poética y Crítica) $=$ 2 Poéticas y 2 Críticas. 
Esta transformación -para parafrasear a Genette- puede molestar o satisfacer: en todo caso, supone otros problemas.

\section{BIBLIOGRAFÍA}

Barthes, Roland. "Littérature/enseignement". CEuvres complètes IV. Paris: Seuil.

Baudelaire, Charles. L'art romantique. Euvres complètes III. Paris: Michel Lévy Frères, 1861. Bayard, Pierre. Le hors-sujet. Proust et la digression. Paris: Minuit, 1996.

Qui a tué Roger Ackroyd? Paris: Minuit, 1998.

"Comment j'ai fait régresser la critique". Pour un critique décalée. Autour des travaux de Pierre Bayard. Comp. Laurent Zimmermann. Paris: Éditions Cécile Defaut, 2010. 19-37.

Bombini, Gabriel. "Didáctica de la literatura y teoría: apuntes sobre la historia de una deuda". Orbis Tertius I, 2-3 (1996): 1-4.

Bombini, Gustavo. La trama de los textos. Problemas de la enseñanza de la literatura. Buenos Aires: Lugar, 2009.

Charles, Michel. L'arbre et la source. Paris: Seuil, 1985. Introduction à l'étude des textes. Paris: Seuil, 1995.

Compagnon, Antoine. Le démon de la théorie. Paris: Seuil, 1998.

Culler, Jonathan. "La critique littéraire et l'université: modèles conflictuels (États-Unis)". Études françaises 23, 1-2 (1987): 75-88.

Literary Theory. A Very Short Introduction. New York: Oxford University Press, 1997.

De Man, Paul. Allegories of Reading. Figural Language in Rousseau, Nietzsche, Rilke, and Proust. New Heaven and London: Yale University Press, 1979.

The Resistance to Theory. Minneapolis: University of Minnesota Press, 1986.

De Staël, Germaine. "De l'Allemagne”. Euvres complètes II. Paris: Firmin Didot, 1871.

Doubrovsky, Serge. "Introductions. Le point de vue du professeur". L'enseignement de la littérature. Comps. Serge Doubvrovsky y Tzvetan Todorov. Paris: Plon, 1971. 11-23.

Eco, Umberto. Los limites de la interpretación. Madrid: Debolsillo, 1990.

Empson, William. Seven Types of Ambiguity. London: The Hogarth Press, 1984.

Escola, Marc. Théorie des textes possibles. Amsterdam: Éditions Rodopi, 2012.

Escola, Marc y Sophie Rabau. "Inventer la pratique : pour une théorie des textes possibles". La lecture littéraire 8. La case blanche. Théorie littérraire et textes possibles. Comps. Marc Escola y Sophie Rabau. Reims: Université de Reims, 2006. 9-28.

Genette, Gérard. "Rhétorique et enseignement". Figures II. Paris: Seuil, 1969.

"Littérature et histoire". L'enseignement de la littérature. Comps. Serge Doubvrovsky y Tzvetan Todorov. Paris: Plon, 1971. 243-251. 
Gerbaudo, Analía. "Pluralismo Teórico y Transferencia Didáctica (o la Literatura en la Encrucijada entre el Relativismo y la Ortodoxia)”. El Hilo De La Fábula 1.1 (2005): 60-67. "Literatura y enseñanza". La investigación literaria. Problemas iniciales de una práctica. Comp. Miguel Dalmaroni. Santa Fe: Universidad Nacional del Litoral, 2009. 165-185.

Iser, Wolfgang. El acto de leer. Teoría del efecto estético. Madrid: Taurus, 1987. How to Do Theory. Oxford: Blackwell, 2006.

Hegel, Georg Wilhelm Friedrich. Lecciones sobre la estética. Madrid: Akal, 1989.

Landow, George. Hipertexto 3.0. Barcelona: Paidós, 2009.

Miller, Hillis. Theory now and then. Durham: Durke University Press, 1991.

Milner, Jean-Claude. El periplo estructural. Buenos Aires: Amorrortu, 2003.

Panesi, Jorge. "La caja de herramientas o qué no hacer con la teoría literaria". El taco en la brea 1 (2014): 322-333.

Richards, Ivor Amstrong. The Philosophy of Rhetorics. New York: Oxford University Press, 1936.

Robin, Regine. "Extension et incertitude de la notion de littérature". Théorie littéraire. Comp. Marc Angenot. Paris: PUF, 1989. 45-49.

Steiner, Peter. El formalismo ruso. Una metapoética. Madrid: Akal, 1984.

Tadié, Jean-Yves. "Avant-propos”. La littérature française: dynamique et histoire, 2 vols. Comp. Jean-Yves Tadié. Paris: Gallimard, 2007. 9-23.

Todorov, Tzvetan. “Conclusion”. L'enseignement de la littérature. Comps. Serge Doubvrovsky y Tzvetan Todorov. Paris: Plon, 1971. 627-635. 